\title{
Arte, ciencia y literatura sagrada en el Siglo de Oro: el reloj nocturno del arzobispo Spínola

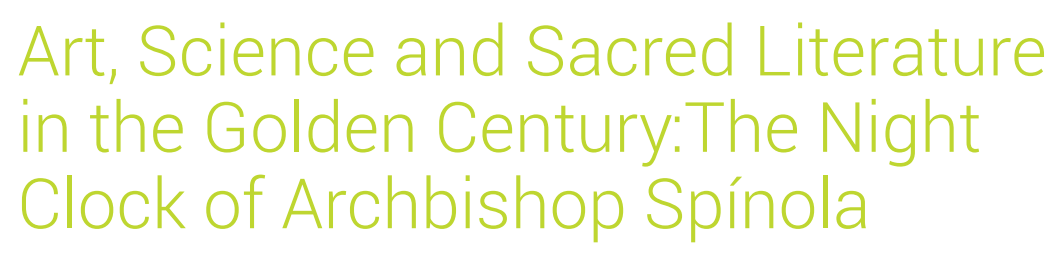

\section{Jesús Rojas-Marcos González}

Departamento de Historia del Arte

Universidad de Sevilla

ESPAÑA

rojasmarcos@us.es

[Hipogrifo, (issn: 2328-1308), 8.1, 2020, pp. 533-551]

Recibido: 17-04-2019/ Aceptado: 02-07-2019

DOI: http://dx.doi.org/10.13035/H.2020.08.01.36

Resumen. En el Barroco europeo se produjo la perfecta integración entre arte, ciencia y literatura sagrada. En el presente artículo ilustramos este fenómeno con el análisis documental, formal, iconográfico y simbólico de un reloj nocturno del Siglo de Oro, tipología excepcional creada en Italia por deseo del papa Alejandro VII. Dicha pieza, de elaboración internacional, perteneció a Ambrosio Spínola, siendo arzobispo de Sevilla (1669-1684). Su mecanismo está firmado en Londres por el relojero Johannes Fromanteel y la pintura del dial, por el artista sevillano Lucas Valdés. La escena representada, recogida en las hagiografías postridentinas del Flos sanctorum, muestra un episodio de la vida del patrón del propietario del reIoj: San Ambrosio absolviendo al emperador Teodosio. El estudio de este artefacto constata la presencia en España de un objeto científico de última tecnología y obra artística de primer orden, cuya pintura tiene su fuente literaria en una de las series biográficas de santos más editadas de la Edad Moderna.

Palabras clave. Reloj nocturno; arzobispo Ambrosio Spínola; Johannes Fromanteel; Lucas Valdés; pintura barroca sevillana; siglo XVII. 
Abstract. In the European Baroque there was the perfect integration between art, science and sacred literature. In this article we illustrate this phenomenon with the documentary, formal, iconographic and symbolic analysis of a Golden Age night clock, exceptional typology created in Italy by desire of Pope Alexander VII. This clock, of international elaboration, belonged to Ambrosio Spínola being archbishop of Seville (1669-1684). Its mechanism is signed in London by the clockmaker Johannes Fromanteel and the dial painting, by the Sevillian artist Lucas Valdés. The scene, collected in the post-Tridentine hagiographies of the Flos sanctorum, shows an episode in the life of the owner of the clock: Saint Ambrose absolves the Emperor Theodosius. The study of this artifact confirms the presence in Spain of a scientific object of last technology and artistic work of first order, whose painting has its literary source in one of the most published biographical series of saints of the Modern Age.

Keywords. Night clock; Archbishop Ambrosio Spínola; Johannes Fromanteel; Lucas Valdés; Sevillian baroque painting; $17^{\text {th }}$ Century.

El Barroco fue una época de esplendor para el arte, la ciencia y la literatura sagrada. De hecho, en las artes plásticas, el desarrollo del naturalismo se comprende mejor a la luz de los hallazgos científicos del momento; en especial, de las aportaciones de Galileo Galilei (1564-1642) respecto a la teoría del movimiento, que confirmaron las ideas copernicanas sobre el heliocentrismo. Desde entonces, el hombre creyó ocupar un lugar diferente en el cosmos y, en consecuencia, transformó su percepción del espacio, de la luz y del tiempo. En este sentido, Panofsky afirma que ningún periodo como el Barroco «ha estado tan obsesionado por la amplitud y profundidad, el horror y la sublimidad del concepto del tiempo», etapa en que la humanidad se encontró enfrentada «con el infinito como cualidad del universo, en vez de ser una prerrogativa de Dios» .

Pese a esta nueva situación - desconcertante para la soteriología-, el arte, la ciencia y la religión se integraron perfectamente, como prueban numerosos objetos de distinta índole y bella manufactura. Entre ellos están los que corresponden al mundo de la relojería, que conocieron un desarrollo espectacular en el siglo XVII. Los avances científicos y las observaciones astronómicas condujeron a los especialistas a precisar con mayor exactitud la medida del tiempo. Baste citar el enunciado de la ley del péndulo simple por parte del referido Galileo, quien al final de su vida pensó aplicarla a la medida temporal. En 1642, su hijo Vincenzo (1606-1649) comenzó la construcción del modelo paterno en un mecanismo relojero, pero quedó inacabado. Los aportes fundamentales los hizo Christian Huygens (1629-1695), al que se considera el inventor del péndulo aplicado al reloj. Bajo sus indicaciones, Salomon Coster (h. 1620-1659), relojero de La Haya, fabricó el primer reloj de péndulo en 1657, de características revolucionarias². 
En el presente artículo analizamos en profundidad uno de estos ejemplares, cuya riqueza estética, mecánica y simbólica ilustra la mencionada integración entre arte, ciencia y religión en el Barroco europeo. Se trata de un reloj nocturno que perteneció a Ambrosio Spínola, siendo arzobispo de Sevilla (1669-1684), al exhibir su escudo eclesiástico (fig. 1)3. Dicha tipología solucionó el viejo problema de consultar la hora en la oscuridad de la noche sin necesidad de tener que oírla por la acústica producida en las medias o cuartos. En la historia de la relojería se ha intentado resolver de diversos modos, desde el reloj de candil al reloj de linterna, pero tales inventos mantenían la luz de la vela o mecha encendida, deslumbrando así a quienes quisieran saber la hora ${ }^{4}$.

El prototipo de mayor aceptación se creó en Italia a mediados del Seiscientos, considerándose uno de los logros más originales de la relojería del país transalpino. Su nacimiento responde al deseo del insomne Alejandro VII (1599-1667). En octubre de 1655, seis meses después de ser elegido papa, propuso a través de su mayordomo, Girolamo Farnese (1599-1668), nombrado cardenal in pectore en 1657, construir un reloj que le mostrara la hora en sus noches de desvelo. Farnese consultó tal posibilidad a Pier Tommaso Campani (1625?-1694?), encargado de los relojes en el Vaticano; y este habló con sus hermanos Matteo (1620-1678) y Giuseppe (1635-1715). Al año siguiente, en 1656, estos tres inventores presentaron al sumo pontífice un prototipo que, además de silencioso, iluminaba la cifra de la hora y el índice de cuarto correspondiente, gracias a una lucerna colocada en su interior ${ }^{5}$.

El invento consistía en una esfera ${ }^{6}$ de gran tamaño para albergar el ingenioso mecanismo. En la parte inferior se incluía una pintura y en la superior se abría un arco con las indicaciones de cuatro cuartos y sus mitades. Por dicha apertura pasaba un disco circular, portador de otros tres, en los cuales se alternaban las cifras horarias de I a XII. A partir de la década de los sesenta se empezó a aplicar el péndulo al reloj. El éxito obtenido les valió a los Campani un privilegio o patente del santo padre. La notoriedad les ofreció la posibilidad de fabricar innumerables nocturnos para reyes, virreyes, cardenales, etc. Tantos fueron los encargos que tuvieron que abrir varios talleres para atenderlos. Además, alguno de sus oficiales se independizó pronto, por lo que el modelo se generalizó incluso fuera de Italia, sobre todo en Austria?.

3. En mayo de 2018 concluimos un breve estudio de este reloj nocturno por encargo de Colnaghi, con motivo de la exposición A Tale of Two Kingdoms. The Art of Spain and Naples, que dicha galería de arte celebró en su sede londinense entre el 29 de junio y el 7 de septiembre de ese año. En aquella aproximación a la obra tuvimos la fortuna de descubrir la firma del pintor Lucas Valdés, cuya identificación no nos ofreció ningún tipo de dudas. Sin embargo, nuestro texto fue modificado en tal aspecto, apareciendo su padre, Juan de Valdés Leal, como autor de la pintura en la página web de la institución, único medio por el que ha sido difundido nuestro trabajo (Rojas-Marcos González, 2018).

4. Montañés, 1986, p. 184; y Montañés, 1991, pp. 14-15.

5. Campani, Discorso intorno a' soui muti Oriuoli..., pp. 1-8. Sobre los Campani ver Egidi, 2011.

6. Término español (incongruente por referirse a una superficie plana) que alude a la parte frontal (o exterior) del reloj, donde se sitúa la escala de las horas, entre otras posibles indicaciones. En este trabajo usaremos asimismo la palabra dial, de origen inglés (Montañés, 1986, pp. 93-95).

7. Montañés, 1986, p. 185. 
Ello explica que la popularidad de esta excepcional tipología alcanzara su apogeo en el último cuarto de la centuria. Los relojes conservados suelen estar montados a partir de piezas de distinta factura y considerable calidad técnica y material 8 . En los comedios del siglo XVIII dejaron de fabricarse por falta de precisión, debido al paso del sistema de los círculos horarios. Por eso, el valor de los nocturnos en el mercado artístico actual resulta extraordinario. En España se contaron por docenas durante el reinado de Carlos II (1661-1700), periodo en que se encuadra el ejemplar que estudiamos, que en origen estuvo en nuestro país. Hoy se localiza un número escaso, entre los que se incluye el del Museo Nacional de Artes Decorativas ${ }^{9}$, con pintura central de La huida a Egipto, cuya maquinaria está firmada en Roma, en 1670, por Joseph de Lellis ${ }^{10}$.

El nocturno de Spínola se enmarca dentro de esos magníficos relojes contemporáneos. Alcanza una altura total de $110 \mathrm{~cm}$. La caja es de madera ebonizada y dorada, con fustes de mármol y apliques en bronce dorado. Por analogía estilística, se ha pensado que su diseño podría corresponder al arquitecto John Webb $(1611-1672)^{11}$. El autor de la maquinaria fue el relojero Johannes Fromanteel, activo en la segunda mitad del siglo XVII e hijo de Ahasuerus Fromanteel (1607-1693). Ambos son conocidos por hacer en Inglaterra los primeros relojes de péndulo, como el que nos concierne. En el mecanismo se lee su firma y el lugar de ejecución: «Johannes Fromanteel / Londini Fecit» (fig. 2). El dial cuadrado, de cobre, mide $28 \times 28 \mathrm{~cm}$. El pintor sevillano Lucas Valdés (1661-1725) representó en él la escena de San Ambrosio absolviendo al emperador Teodosio, firmada así en el ángulo inferior derecho: «D. N Lucas / de Val/des / FACIEBAT» (figs. 3-4).

Tan excelente pieza, hoy en colección particular, fue subastada en 2016 por la casa Aste di Antiquariato Boetto, de Génova, donde salieron a puja enseres de la familia Spínola ${ }^{12}$. En efecto, este reloj fue encargado por o para Ambrosio Spínola y Guzmán, a quien perteneció mientras ocupó la sede hispalense (1669-1684). Dicho prelado nació en Madrid en 1632. Era hijo de Diego Mesía Felípez de Guzmán y Policena Spínola, marqueses de Leganés. Su tío el cardenal Agustín Spínola (1597-1649), también arzobispo de Sevilla (1645-1649), se ocupó de su tutela y su formación, así como de la promoción de su carrera eclesiástica. Antes de la mitra hispalense, fue obispo de Oviedo (1665-1667) y arzobispo de Valencia (1667) y de Santiago de Compostela (1668-1669). Según la biografía del canónigo sevillano Juan de Loaysa (1633-1709), publicada poco después de su óbito en 1684, su pontificado se caracterizó por la labor evangelizadora, por las misiones apostólicas y,

8. Variados ejemplos de relojes nocturnos se pueden ver en Brusa y Del Vecchio, 1971; Brusa, 1975; Montañés, 1986, pp. 194 y 222; Gregato, 2000; Brusa, 2000; González-Palacios, 2004, pp. 104-109; Thompson, 2004, p. 72; Bedini, 2005; Gregato y Pippa, 2006; y Garnier y Hollis, 2018, núm. 43.

9. Montañés, 1986, p. 185. Reproducido en Echeverría, 1979, p. 109.

10. Núm. de inventario 02037 (<http://ceres.mcu.es/pages/Main>, consultado el 8 de agosto de 2019).

11. Agradecemos esta información al experto en relojería antigua Sebastian Whitestone, quien nos transmitió su parecer con ocasión de nuestro primer estudio sobre el reloj (ver nota 3). Así se publicó después en Garnier y Hollis, 2018, núm. 58 (también se relacionan con Webb los núms. 18, 34, 48 y 49). Sobre este arquitecto ver Bold, 1989.

12. Aste di Antiaquariato Boetto, 2016, lot. 199, pp. 156-157. 
fundamentalmente, por la práctica de la caridad con los más necesitados ${ }^{13}$. De ahí que, gracias a su espléndida generosidad, fuera llamado el «padre de los pobres» ${ }^{14}$.

Sobre su relación con el arte, Spínola estuvo desde su niñez en contacto directo con obras de los grandes maestros. La colección de su progenitor superó las 1.300 pinturas y, entre 1639 y 1644, vivió en el Alcázar Real como menino del príncipe Baltasar Carlos (1629-1646). Además, durante su estancia en Sevilla junto a su tío el cardenal, estudió Artes en el Colegio de Santa María de Jesús. Sin embargo, a tenor de la documentación conservada, no parece que llegara a formar una colección en sentido estricto. Se sabe que poseyó varias decenas de pinturas, de temática religiosa o retratos; y esculturas de pequeño formato, todas ellas imágenes de devoción. En su testamento, fechado el 16 de diciembre de 1679, se citan cuadros de Van Dyck, Tiziano, Cigoli, Bazán, Brandi y Murillo ${ }^{15}$; y una Inmaculada Concepción del escultor Pedro Roldán ${ }^{16}$.

En cuanto al tema que nos ocupa, en el documento testamentario se mencionan cinco relojes, que el arzobispo manda a las siguientes personas: al padre Tirso González, de la Compañía de Jesús, catedrático de prima en la Universidad de Salamanca, «un reloj despertador de faltriquera para su gobierno en el santo ejercicio de las misiones»; a Cosme Pardo de la Casta, racionero de la catedral de Sevilla, «un relojillo de oro de faltriquera [que] tiene parte de porcelana y caja de acero»; al Conde de los Arcos, su primo, «un reloj de bronce dorado guarnecido con láminas de plata sobre un sátiro también de plata»; a Francisco Esteban del Vado, de la Santa Inquisición, «un reloj de campana, cuartos y repetidor de bronce dorado, que está en una caja guarnecida de cuero y cantoneras doradas»; y a Bernardo de Urbina, su caudatario, «un reloj de péndola con su caja grande de ébano imitado que vino de Roma» ${ }^{17}$.

Como revela la documentación, los relojes tienen una relevancia notable entre las pertenencias del arzobispo. Dada su creciente variedad a partir del Quinientos, el uso y la posesión de estos sofisticados instrumentos se extendieron durante el siglo XVII. Adquirieron importancia social, al formar parte de ambientes caracterizados por el lujo, el boato y la distinción. Por tanto, su ostentación, sobre todo de los relojes muebles, se consideraba un termómetro de opulencia y signo externo de riqueza ${ }^{18}$. Desde el Renacimiento, reyes, nobles y clero de primer orden mostra-

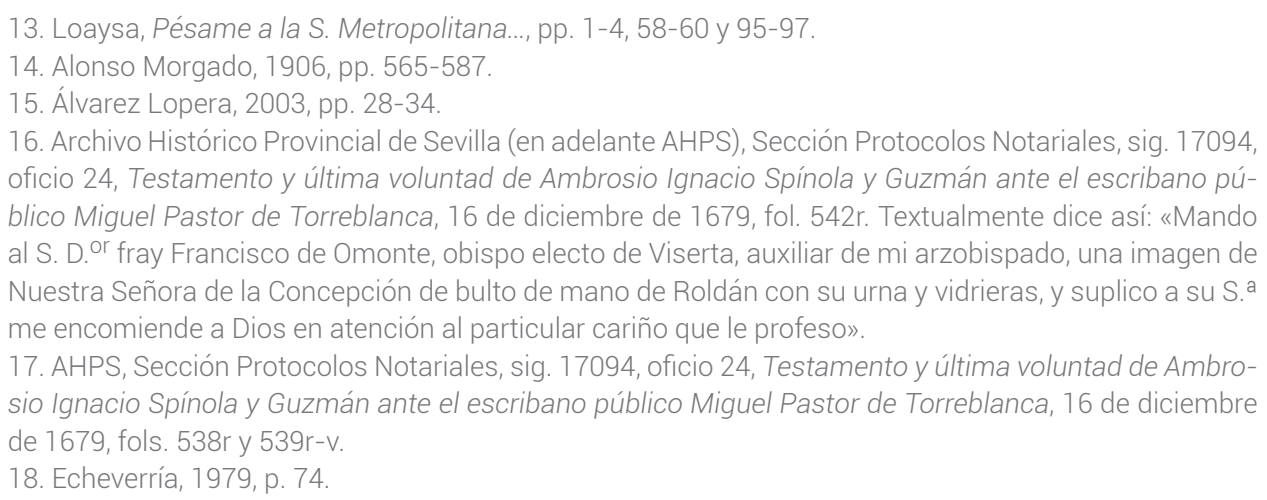


ron interés por estos objetos preciosos, cuyo progresivo enriquecimiento material y técnico equiparó su valor al de las piezas de joyería, orfebrería, tapicería y mobiliario. Se convirtieron, pues, en expresión emblemática de su actividad profesional y de sus cualidades personales ${ }^{19}$.

El arzobispo Spínola pudo heredar el aprecio por estos artefactos de su padre, quien poseyó «relojes trasordinarios», como dice Vicente Carducho (h. 1576-1638) en sus Diálogos de la pintura (1633) ${ }^{20}$. Tenía inventariados veintisiete, expuestos todos juntos en la galería baja de su palacio madrileño, de los cuales tres, al menos, con autómatas ${ }^{21}$. Al igual que en el caso de las artes plásticas, tampoco se puede afirmar que los ejemplares del prelado referidos en el testamento formaran una colección sensu stricto. Sin embargo, destacan por su variedad, ya que presentan distintos tamaños, mecanismos y usos; y por su calidad material, al estar elaborados en oro, plata, bronce dorado o porcelana. Son tanto relojes portátiles de uso personal como relojes muebles de sobremesa.

Nos resulta de esencial interés el último de los reseñados en el testamento pues, a juzgar por la sucinta descripción, es probable que se identifique con nuestro reloj, por varios motivos. Primero, por ser su mecanismo de péndulo; segundo, por decir que su caja es «grande», como requiere la tipología nocturnal; tercero, por ser esta de «ébano imitado», correspondiéndose con la madera ebonizada de nuestro ejemplar; y, cuarto, por proceder de Roma, teniendo en cuenta el origen italiano de la familia Spínola, sus permanentes contactos con Italia y, en concreto, el lugar de invención de los relojes nocturnos. Siendo cautos, no hay que olvidar que la caja y el mecanismo de la pieza que nos incumbe fueron realizados en Londres y que el dial se pintó en Sevilla.

Con independencia de que sea el reloj aludido en el testamento, ignoramos por ahora las circunstancias exactas que rodean a la obra. Contener el escudo del arzobispo refuerza la hipótesis de que se trate de un encargo personal. Al respecto, se ha planteado que una comisión de Spínola pudo llegar a Fromanteel a través de su prima Catalina Enriqueta de Braganza (1638-1705), esposa del rey Carlos II de Inglaterra (1630-1685)22. Empero, no hay que descartar la posibilidad de que fuera un regalo familiar o diplomático. Por ejemplo, desde Milán, su primo Pablo Spínola Doria, III marqués de los Balbases (1628-1699), le hizo uno consistente en una «Cruz muy grande de plata sobredorada, llena de grandes Reliquias», que «se apreciaba en dos mil pesos» ${ }^{23}$. Además, en el siglo XVII, los jesuitas, a quienes el prelado protegió y de los que siempre se rodeó, hicieron de los relojes mecánicos sus regalos más preciados ${ }^{24}$.

Desconocemos asimismo el espacio que el nocturno ocupó en las dependencias palatinas, pero cabría esperar que su ubicación facilitara su contemplación

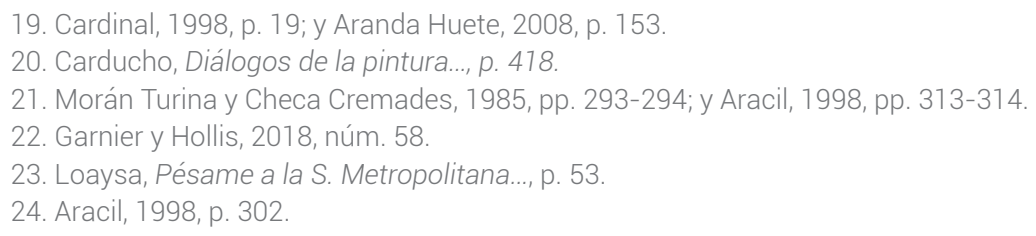


a un círculo social no excesivamente restringido. Tampoco sabemos el rol que desempeñó entre las pertenencias del arzobispo, no obstante, es presumible que se expusiera como destacado signo visual de las virtudes de su propietario. Pese a la falta de certezas, el simple hecho de poseer esta clase de objeto, de enorme riqueza formal y avanzada tecnología, manifiesta que Spínola fue hombre de sensibilidad artística, de preocupación por su reflejo social y de espíritu erudito; es decir, una pieza de ese calibre evidencia un gusto exquisito ya sea como mecenas o como coleccionista, una conciencia plena de la imagen que deseaba proyectar y un conocimiento actualizado de los ambientes científicos del Barroco europeo.

Hecha la contextualización de nuestro reloj, procedamos con su análisis. Su caja se inspira en el elegante clasicismo de los modelos italianos de altar ${ }^{25}$. De base rectangular, se alza gracias a un zócalo decorado con apliques de guirnaldas florales y un mascarón en el centro. Encima se levantan dos columnas que enmarcan el dial y sustentan el entablamento. Los fustes acanalados de mármol brecha, en tonos grisáceos, no tienen precedentes en los relojes fabricados por los Fromanteel. En cambio, el detalle de los capiteles corintios dorados es típico de las cajas que encierran los mecanismos de estos relojeros, como demuestran abundantes ejemplos ${ }^{26}$.

En la zona superior, el friso se embellece con una guirnalda floral tripartita, fijada con rosetas, en la que campean tres cabezas infantiles. El frontón curvo partido luce en el tímpano estilizadas hojas de acanto que parten de un mascarón leonino central. Entre las volutas del frontón se dispone un jarrón y sobre ellas se eleva un ático rematado con perfil serliano. En los cuatro ángulos de su superficie se ornamenta con sendos flameros. El conjunto se corona con una áurea escultura de Atenea, que también aparece en otro reloj de Johannes Fromanteel en madera de palo rosa 27 . Esta diosa griega de las artes y los oficios se identifica con la Sabiduría, que el hombre alcanza en la ancianidad, tras el inexorable paso del tiempo. Así lo recuerda el propio reloj que, al ser barroco, insiste en la transitoriedad de la vida y, al estar concebido para un arzobispo, alaba la exactitud moral del prelado28.

En la pintura, la escena queda enmarcada por dos columnas de fustes marmóreos y capiteles jónicos sobre pedestales. Precisamente, en el pedestal derecho descubrimos la firma de su autor: Lucas Valdés, del cual trataremos más adelante. De momento apuntamos que era hijo del célebre Juan de Valdés Leal (1622-1690), a quien Spínola encargó, en 1673, una serie de pinturas sobre la vida de san Ambrosio (340-397) para el oratorio de su cuarto bajo en el Palacio Arzobispal ${ }^{29}$. Entre los pasajes de ese ciclo se halla San Ambrosio absolviendo al emperador Teodosio, rara vez representado en la iconografía del santo y carente de tradición pictórica.

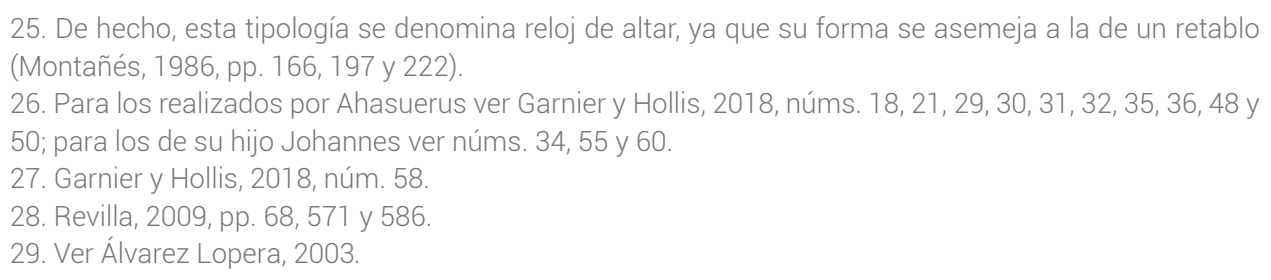


Por ello, es de suponer que Lucas Valdés se apoyaría en la interpretación de su padre, hoy en el Museo del Prado, para la ejecución de este óleo.

Las citadas columnas sostienen una estructura arquitectónica compuesta por dos molduras en forma de «ces» o costillas, que dulcifican los ángulos rectos del perfil de la pintura. Se engalana en el centro con una guirnalda floral. Las flores simbolizan, asimismo, la fugacidad terrenal -en consonancia con el paso del tiempoy las virtudes de san Ambrosio - patrón del propietario del reloj-. En los extremos superiores, bajo las costillas, sobrevuelan seis ángeles niños en caprichosas posturas. Unos, al gusto barroco, descorren una gran cortina, permitiendo contemplar la escena; y otros portan los atributos del santo. Los de la izquierda llevan la mitra y el báculo, al ser nombrado obispo de Milán; y los de la derecha, un libro, como Doctor y Padre de la Iglesia latina ${ }^{30}$.

La historia representada en el reloj fue recogida, entre otros, por Santiago de la Vorágine en su Leyenda dorada, escrita hacia 1264; y por Pedro de la Vega († 1541), Pedro de Ribadeneyra (1526-1611) y Alonso de Villegas (1533-1603) en sus ediciones del Flos Sanctorum o libro de las vidas de los santos. Se dice que en 390 se produjo en Tesalónica una sedición, en la que fueron apedreados los jueces de la ciudad. Teodosio prometió a san Ambrosio perdonar la ofensa. Sin embargo, incumplió su promesa. Ordenó al ejército atacar a la población, provocando una matanza en la que murieron miles de personas. De inmediato, el santo dictó la excomunión del emperador, que se encontraba entonces en Milán, y le prohibió entrar en su iglesia. Teodosio le pidió la absolución, pero san Ambrosio le impuso hacer pública penitencia si quería ser admitido de nuevo en el templo. En la Navidad de ese año, el emperador se despojó de su vestimenta y se postró ante el obispo, obteniendo así su perdón ${ }^{31}$. Tal episodio alude a la armonía entre los poderes espiritual y temporal, reconociendo siempre la superioridad de la Iglesia en los asuntos morales. De ese modo se expresaría el ideal del buen gobierno para el arzobispo Spínola y sus asesores ${ }^{32}$.

La acción se sitúa en un agreste exterior. Los personajes se distribuyen en dos grupos bien diferenciados, encabezados por los protagonistas. A la derecha, Teodosio, arrodillado, junta sus manos en actitud reverencial e inclina la cabeza, ya descubierta, con humilde expresión. Luce armadura y capa, sostenida por un paje. Un cortesano sujeta la corona, mientras otro gesticula sorprendido ante la disposición del soberano. Absorta queda también la soldadesca que completa el séquito, haciéndose eco de la intensa emoción que se respira en la escena. En el lado contrario, san Ambrosio se coloca sobre una escalinata, presumiblemente a las puertas del templo. Viste de medio pontifical, con alba, estola y capa pluvial recogida en sus orillas por el caudatario. El blanco de su vestimenta se corresponde con el color litúrgico empleado en Navidad. Como insignias pontificales se toca con mitra, símbolo de su autoridad; lleva el báculo pastoral en la mano izquierda y luce en la

30. Réau, 2000, pp. 68-72.

31. Vorágine, La leyenda dorada, vol. 1, pp. 246-247; Vega, Flos Sanctorum, fol. 8v; Villegas, Flos Sanctorum, fols. 420-421; y Ribadeneyra, Flos Sanctorum, p. 615.

32. Álvarez Lopera, 2003, pp. 48, 51-52 y 84-87. 
diestra el anillo episcopal. El obispo de Milán, con toda solemnidad, se inclina para bendecir y absolver al emperador de los romanos. Los religiosos que lo acompañan, admirados ante los hechos, visten la sobrepelliz encima del traje talar y portan las Sagradas Escrituras y la Cruz alzada.

El esquema compositivo de la pintura, simétrico y equilibrado, está centrado por el escudo eclesiástico de Ambrosio Spínola, sostenido en vuelo por dos angelitos. Lo enmarca una cartela barroca de color rojo y, al ser arzobispo, está puesto sobre la cruz de procesión de doble travesaño y se remata con el capelo, del que penden las diez borlas a cada lado propias de ese grado de la jerarquía eclesial. Por esta razón, no es descartable que Lucas Valdés, tal y como hiciera su padre en la serie pictórica de 1673, reprodujera en el rostro de san Ambrosio los rasgos del arzobispo Spínola ${ }^{33}$. En efecto, su aspecto parece recrear mutatis mutandis las facciones del prelado hispalense, aunque más envejecido que en el ciclo de Valdés Leal.

En este sentido, si se trata del reloj mencionado en el testamento, sería admisible que en el caudatario estuviese retratado, en su mocedad, Bernardo de Urbina, a quien fue legado. Dicho clérigo, nacido casi con seguridad en el municipio de Armiñón (Álava), ya residía en Sevilla en $1670^{34}$. Una década después era medio racionero de la catedral, prebenda que su hermano Juan obtuvo en $1678^{35}$. Ese año consta como gentilhombre de cámara de Ambrosio Spínola ${ }^{36}$ y al siguiente, como sabemos por el testamento, como su caudatario. En 1696, siendo canónigo del Cabildo, se le asignó una capellanía en la parroquial de Santa María de Orduña (Vizcaya) ${ }^{37}$, a la que ya había renunciado en $1715^{38}$. Pero lo más interesante es que en 1710 se publicó una oración panegírica de Juan de Gámiz con motivo del traslado de los restos mortales del cardenal Spínola y de su sobrino el arzobispo desde la iglesia de la casa profesa de la Compañía de Jesús al nuevo templo del colegio de la Purísima Concepción, vulgo de las Becas. El Dr. Manuel Guarin, que la dio a la

33. Reproducidos en el retrato que en 1670 le hiciera Pedro Núñez de Villavicencio (González Ramos, 1999, núm. 3, pp. 132-133)

34. Archivo de la Diputación Foral de Álava (en adelante ADFÁ), sig. ATHA-DAH-FVAR-036-005-04, Carta de poder otorgada por Bernardo de Urbina, residente en Sevilla, a favor de su hermano Juan de Urbina para que pueda cobrar de Diego de Salazar, patrón de las memorias y obras pías que en Orduña fundó Juan de Tertanga Salazar, lo que le pueda pertenecer de la herencia dejada por su tío, el dicho Juan de Tertanga Salazar, 14 de enero de 1671.

35. Salazar Mir, 1995, vol. 1, pp. 189-190 y 194-195, núms. 423 y 434.

36. ADFÁ, sig. ATHA-DAH-FVAR-036-005-09, Carta de pago otorgada por Bernardo de Urbina, gentilhombre de cámara del obispo de Sevilla, a favor de Diego de Tertanga Salazar, vecino de Madrid y patrón de las memorias y obras pías que en Orduña fundó Juan de Tertanga Salazar, por la obra pía concedida para sus estudios, 1 de febrero de 1678.

37. ADFÁ, sig. ATHA-DAH-FVAR-038-005-10, Diego de Urbina, en nombre de Diego José de Urbina, patrón de las memorias y capellanías que en Orduña fundó Juan de Tertanga Salazar, nombra a Bernardo de Urbina, canónigo de la catedral de Sevilla, capellán de una capellanía de 500 ducados de renta anual, vacante por muerte de José Joaquín de Urbina, 30 de junio de 1696.

38. ADFÁ, sig. ATHA-DAH-FVAR-038-002-02, Diligencias instruidas a causa de la provisión de una capellanía de 500 ducados de renta anual que, en la iglesia de Santa María de Orduña, fundó Juan de Tertanga Salazar, vacante por renuncia de Bernardo de Urbina y solicitada por Diego Manuel Arias, alcalde de Estavillo y Armiñón, para sus hijos, 20 de septiembre a 21 de noviembre de 1715. 
imprenta, la dedicó «al Sr. D. Bernardo de Urbina, Canónigo de la Santa Iglesia de Sevilla, el más antiguo de los Familiares del IImo. Señor Don Ambrosio»39.

Volviendo a la pintura, en torno al escudo, el dial presenta la consabida apertura de los relojes nocturnos, aquí en arco de medio punto. En su borde superior, las perforaciones indican, según tamaño y forma, cuatro cuartos y sus mitades. El disco que pasa por tal apertura deja ver, a través de dos orificios circulares, la hora en números romanos que muestran los discos interiores. Este complejo dispositivo sigue cumpliendo su función en plena oscuridad, merced a la luz emitida desde dentro del reloj (fig. 5). En el disco principal dos grupos de tres ángeles niños revolotean en un fondo azul celeste. Con sus juguetonas poses manifiestan la alegría propia de la infancia y contribuyen a acentuar el sentido giratorio de esta pieza hacia la derecha. Gracias a tan avanzado ingenio, estos mensajeros de Dios, al adquirir movimiento, cobran vida, haciendo realidad el deseado dinamismo de las representaciones artísticas del Barroco.

En 2016, la pintura fue restaurada en Milán por el Dr. Zapolini, que reintegró las capas pictóricas desprendidas, especialmente las de las zonas situadas alrededor de los cuatro puntos de fijación del dial. Esa intervención ha permitido valorar los aciertos de Lucas Valdés en esta singular obra. Con el descubrimiento de su autoría ampliamos el conocimiento sobre este artista de transición entre los siglos XVII y XVIII, cuya autonomía y originalidad se viene reivindicando en los últimos años ${ }^{40}$. En el panorama hispalense despunta por sus decoraciones murales, como las de las iglesias del Hospital de los Venerables (1686/1688-1700)47, del antiguo convento dominico de San Pablo, actual parroquia de la Magdalena (h. 1709-1715); y de la jesuítica de San Luis de los Franceses (h. 1715-1719) ${ }^{42}$. En cambio, esta creación para un reloj nocturno responde a una tipología única en su versátil producción y, que tengamos constancia, en la historia de la pintura sevillana. También resultan inéditos en su quehacer el tema ambrosiano y el soporte material de cobre.

Sobre la datación de la pintura puede plantearse una interrogante: ¿en qué año acometió el artista su tarea? Los especialistas en relojería no dudan en fechar la maquinaria de Johannes Fromanteel hacia $1670^{43}$. Por entonces, Lucas Valdés, nacido en 1661, aún sería casi un niño. Recordemos que con diez y once años ya dio muestras de su precoz valía al rubricar varios emblemas grabados al aguafuerte para el libro Fiestas de la S. Iglesia Metropolitana, y Patriarcal de Sevilla, al nuevo culto del Señor Rey S. Fernando el Tercero de Castilla y de León, escrito por Fernando de la Torre Farfán en 1671; publicación de la que su padre fue el director artístico ${ }^{44}$.

39. Gámiz, Oración panegírica..., p. 1.

40. Quiles García, 1990, pp. 228-230; Pérez Sánchez, 1992, pp. 416-417; Morales, 1993; Herrera García, 2000; Valdivieso, 2003, pp. 472-488; Fernández López, 2003; Fuentes, 2009; y Caravaca de Coca, 2017. 41. Sobre el techo de la sacristía de este templo ver Fuentes, 2009, pp. 203-207; y Pino León, 2015, pp. 100-116.

42. Fernández López, 2003, pp. 63-73 y 76-82.

43. Garnier y Hollis, 2018, núm. 58.

44. Fernández López, 2003, pp. 16-17 y 141-142. 
No obstante, nos obligan a retrasar algo la datación el ciclo de san Ambrosio pintado por Valdés Leal en 1673 (en cuyo modelo de la absolución de Teodosio se inspiraría su hijo), el venerable aspecto del santo en el óleo del reloj (que reproduce quizás el de Spínola en su ancianidad) y, sobre todo, la inclusión en su firma del «don». Dicho tratamiento de respeto, que distingue socialmente a Lucas Valdés, ha de figurar en virtud del grado académico que alcanzó, al que aludiremos a continuación. Su presencia se constata en la documentación y en las obras firmadas, al menos, desde $1686^{45}$. Esta del nocturno debe de ser anterior, pues se supone que no rebasaría la fecha de 1684, cuando falleció el prelado; o la de 1679, si se trata del reloj del testamento. Las circunstancias del arzobispo en torno a este último año parecen indicar que su ejecución fue previa, ya que, si nos basamos en Loaysa, «para la necesidad común, hasta los cuadros, colgaduras, vajilla de plata, sillas, y escritorios los hubo de convertir en pan» durante «los fatales años de la hambre (que fueron los de 78 y 79)» ${ }^{46}$. De cualquier manera, estaríamos ante su primera pintura conocida.

Entre 1673 y 1679, Lucas Valdés, pese a su juventud, pudo estar capacitado para abordar una pintura que, por formar parte de un artefacto mecánico, implicaba una dificultad añadida, ardua de superar para una mano no avezada. Acerca de los estudios que cursó, desde antiguo se ha señalado la preocupación paterna por procurarle una formación humanística y científica superior a la de los artistas sevillanos contemporáneos. Ceán Bermúdez dice que, antes de enseñarle pintura, "quiso que aprendiera la latinidad y las matemáticas con los jesuitas» ${ }^{47}$. Razón por la que se estima que, a partir de los cuatro años, iniciaría sus estudios en el colegio ignaciano de San Hermenegildo, la institución docente más prestigiosa de Sevilla en el siglo XVII8. Se ha supuesto que dicho establecimiento siguió los pasos de los Reales Estudios del Colegio Imperial de Madrid ${ }^{49}$, que en el último tercio de la centuria, según el padre Poza, disponía de dos cátedras de matemáticas, divididas en dos turnos: en el de mañana, un maestro leería las disciplinas de «la Esfera, Astrología, Astrolabio, Perspectiva y Pronósticos»; y en el de la tarde, otro maestro haría lo propio con las de «Geometría, Geografía, Hidrografía y de Relojes» ${ }^{50}$.

En el caso de nuestro artista, una preparación así de sólida explicaría su alabado dominio de la perspectiva y su especial habilidad para la arquitectura ilusionista. Además, este bagaje lo facultó para ser nombrado, en abril de 1719, maestro instrumentario [sic] de la Academia de la Real Compañía de Guardias Marinas de Cádiz, donde ejerció como profesor de matemáticas hasta su muerte en $1725^{51}$. Pero, sin duda, una formación científica tan completa, que incluía una materia específica

45. Fernández López, 2003, pp. 16-17 y 19 (al objeto de nuestro trabajo, señalamos que en la p. 128, núm. 38, dicho autor rectifica la autoría de un Santiago en la batalla de Clavijo, que lleva la firma y la fecha «D. Lucas De bal/Des Leal. 1677», a favor de un modesto pintor anónimo).

46. Loaysa, Pésame a la S. Metropolitana..., p. 82.

47. Ceán Bermúdez, 1800, p. 104.

48. Fernández López, 2003, p. 16.

49. Fuentes Lázaro, 2009, p. 208.

50. Simón Díaz, 1952, p. 82; y Capel, 1980, pp. 1-35

51. Caravaca de Coca, 2017, pp. 462-469. 
de «Relojes», sería uno de los motivos que justificara su designación para la decoración pictórica del nocturno de Spínola. En este asombroso ingenio supo integrar arte y tecnología al gusto europeo de la época, como prueban los angelitos del disco al actuar a modo de autómatas ${ }^{52}$. De ahí que el hallazgo de esta obra enfatice la condición de Lucas Valdés como prototipo de pintor ilustrado ${ }^{53}$.

Asimismo, la participación del pintor en un objeto de esta categoría es un indicio de su posible relación de mecenazgo con el arzobispo, patrocinio que se confirmaría si se demostrara que el reloj fue un encargo directo del prelado. Defiende esta hipótesis el hecho de que ambos mantuvieron estrechos vínculos con la Compañía de Jesús. Ambrosio Spínola, cuyo segundo nombre era Ignacio, como el fundador, apoyó decididamente a los jesuitas, «en cuyas manos se crio y con ellos murió a su cabecera». Les dio limosnas, se hospedó en sus casas, realizó con ellos los Ejercicios espirituales, hizo imprimir sus catecismos, que repartió en las diócesis que gobernó; los tuvo por confesores y les encargó misiones apostólicas ${ }^{54}$. Es más, en su testamento mandó ser enterrado junto a su tío el cardenal en el templo del referido colegio jesuítico de las Becas. En dicho documento «se reconoció la suma piedad, y el amor que siempre tuvo en vida a la Sagrada Religión de la Compañía de Jesús», según Loaysa ${ }^{55}$. Respecto a Lucas Valdés, desde su temprana educación hasta sus últimos trabajos, se desenvolvió en la órbita cultural de los jesuitas, quienes ya concertaron con su padre la serie de san Ignacio para la mencionada casa profesa $(1660-1664)^{56}$.

Por consiguiente, el posible mecenazgo, que sin duda habría sido favorecido por Valdés Leal, pudo estar propiciado por esta coyuntura. Esa sería, pues, otra de las razones que, a ojos del arzobispo Spínola, acreditara al joven Lucas para ser elegido pintor del dial. Entre los méritos técnicos de la pintura examinada, destacan la claridad y simetría de la composición, que facilita la comprensión de los hechos; la rigurosa minuciosidad en los detalles, típica de su estilo; el colorido rico y jugoso, que contrasta a la perfección con los tonos cromáticos de la caja; así como el dominio de los matices lumínicos y de la perspectiva, que recrea con soltura la ilusión espacial de la tercera dimensión. En definitiva, su poética, adaptada con naturalidad al conjunto y a las exigencias tecnológicas, facilita la correcta lectura e interpretación simbólica del reloj nocturno, instrumento de medición donde se integran deliciosamente el arte, la ciencia y la literatura sacra del Barroco.

52. Sobre relojes con autómatas ver Aracil, 1998, pp. 297-315 y 360-375.

53. Sobre ciencia y arte en la España ilustrada ver Vega, 2010. Para relojes en la Corte española del siglo XVIII ver Aranda Huete (comp.), 2011.

54. Entre los misioneros más allegados estaba el citado padre Tirso González, heredero de uno de sus relojes.

55. Loaysa, Pésame a la S. Metropolitana..., pp. 24 y 103. Curiosamente, Loaysa recurrió a Lucas Valdés en 1695 para la ejecución de un dibujo del Monumento de Semana Santa de la Catedral de Sevilla (Morales, 1993, pp. 160-161)

56. Fuentes Lázaro, 2009, pp. 199-200 y 208-210. 


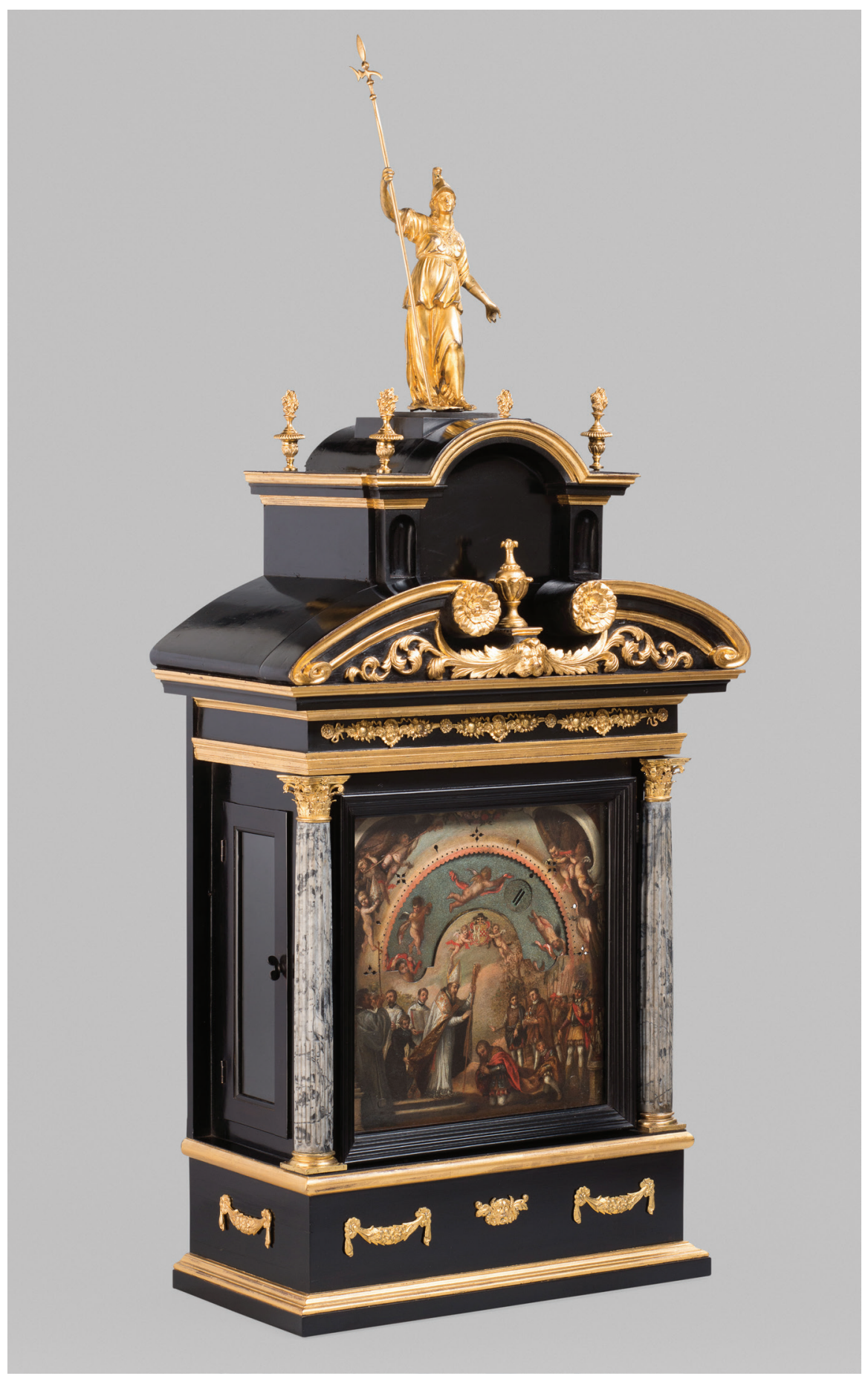

Fig. 1. Johannes Fromanteel y Lucas Valdés, Reloj nocturno del arzobispo Spínola 


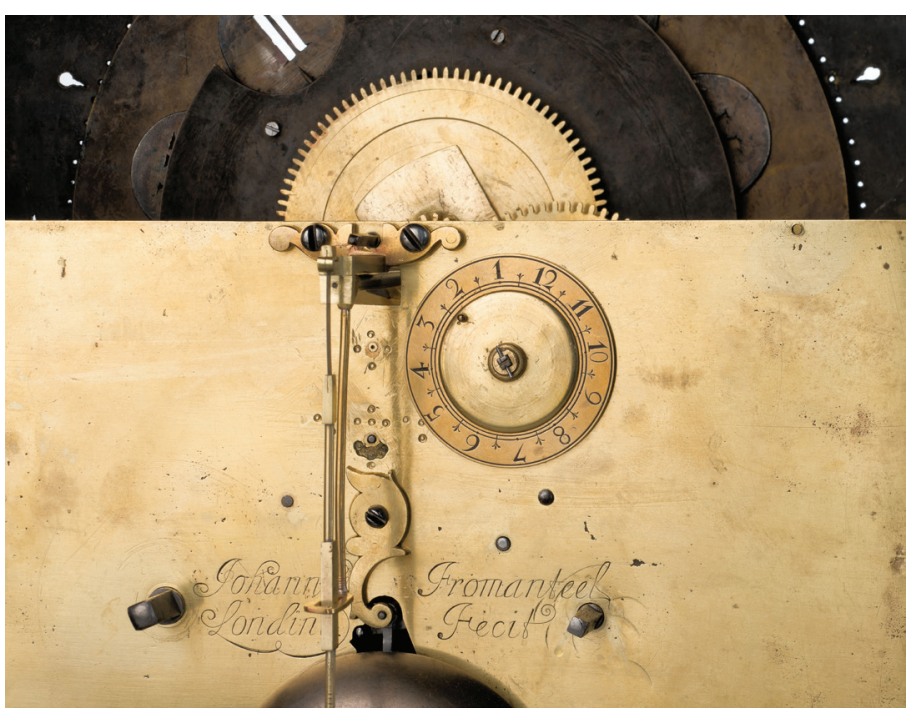

Fig. 2. Firma de Johannes Fromanteel en la maquinaria del reloj

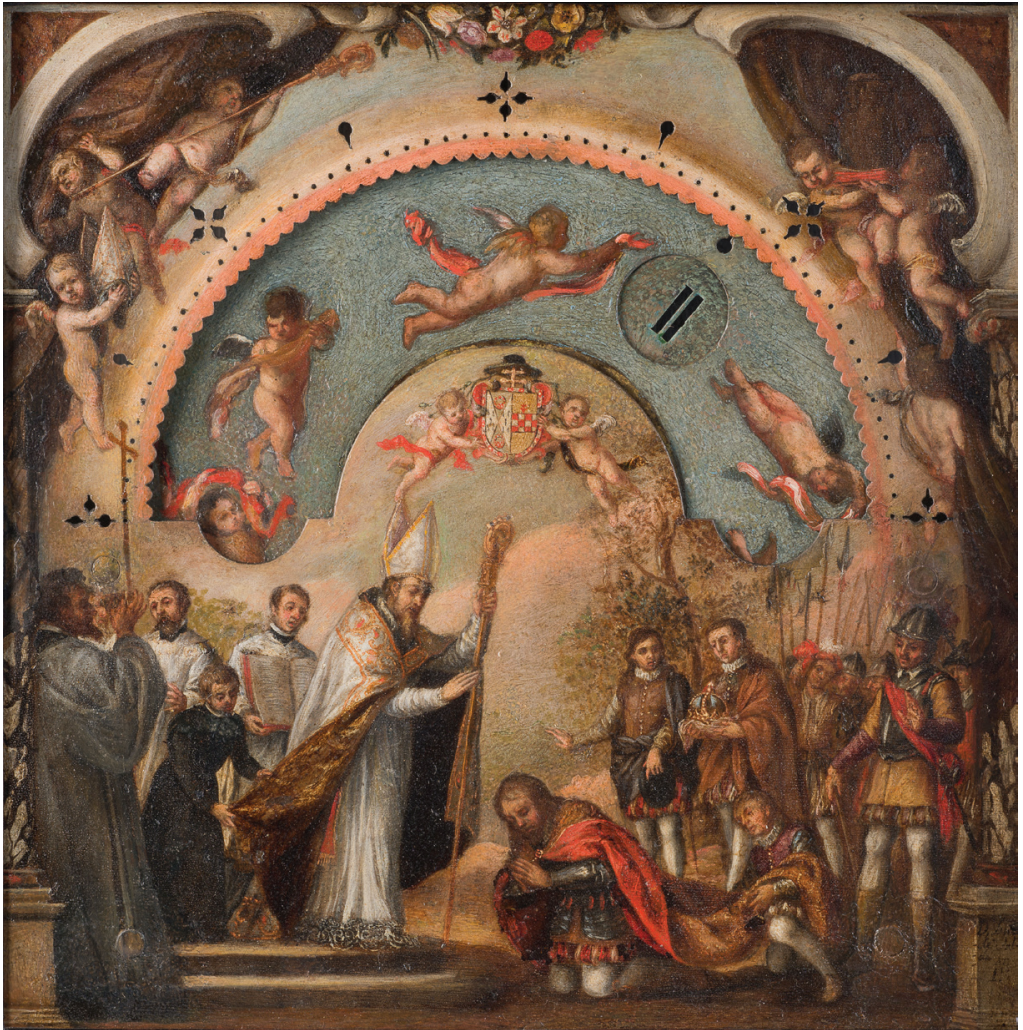

Fig. 3. Lucas Valdés, San Ambrosio absolviendo al emperador Teodosio, óleo sobre cobre, $28 \times 28 \mathrm{~cm}$ 


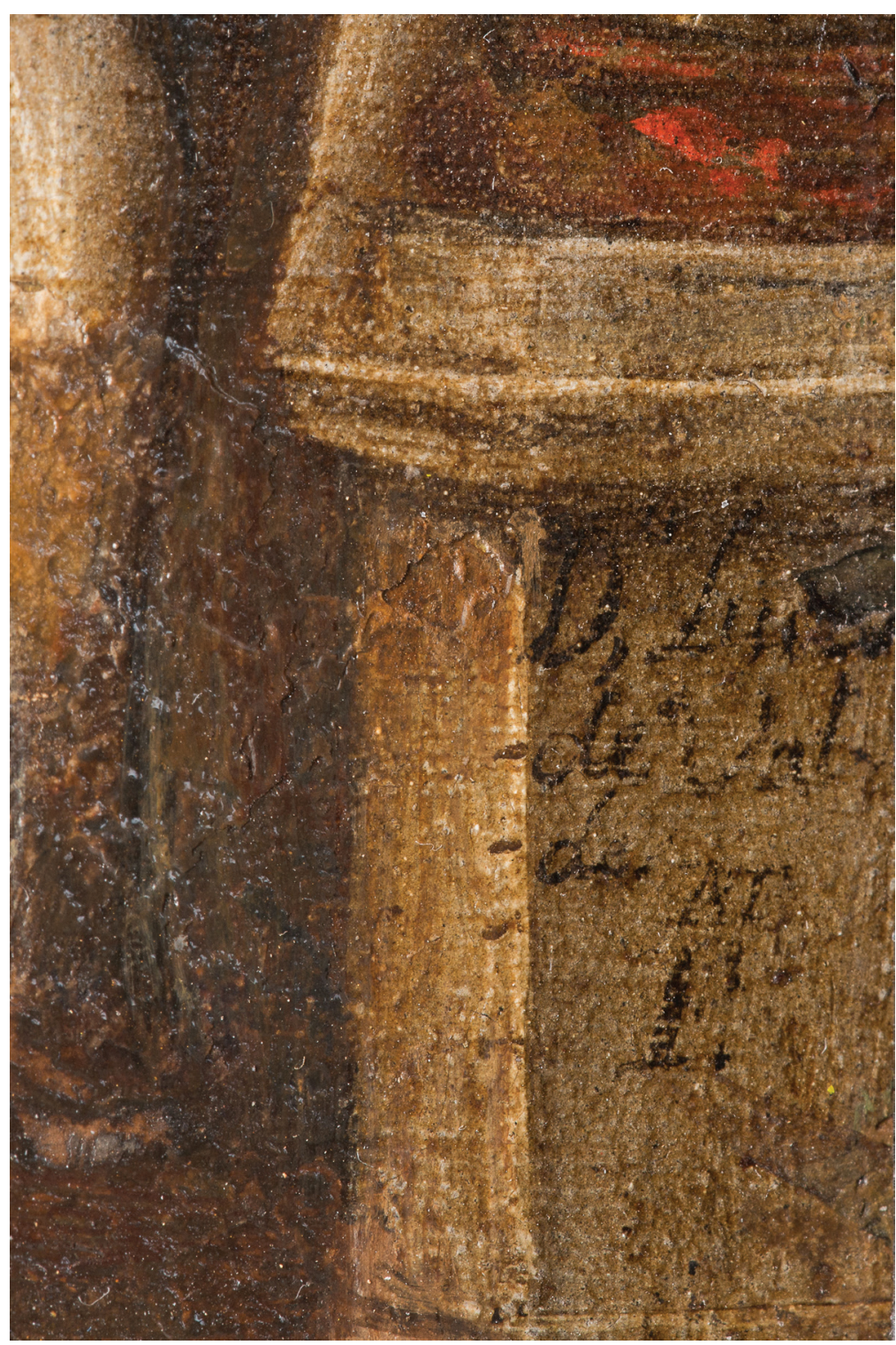

Fig. 4. Detalle de la firma de Lucas Valdés 


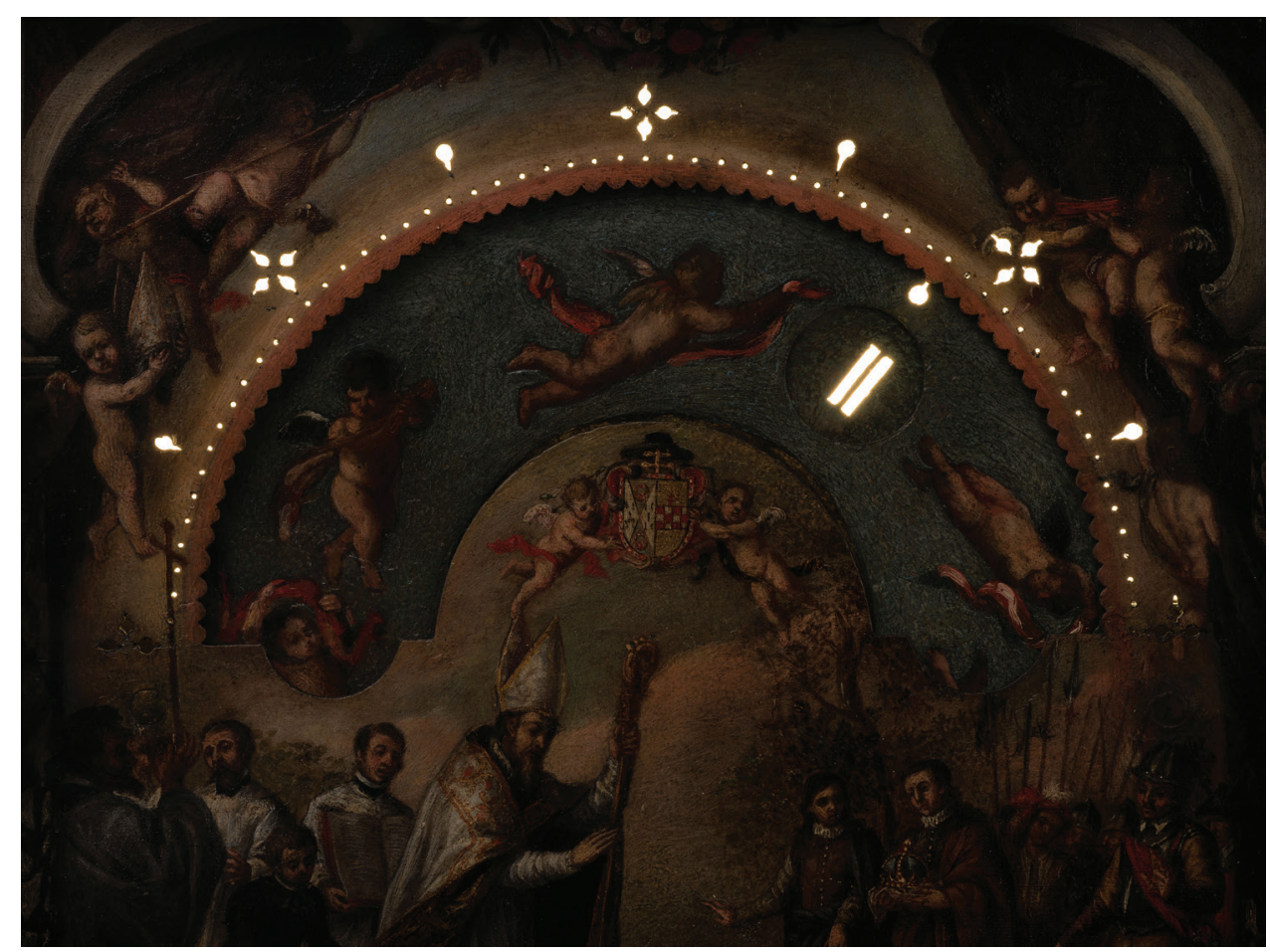

Fig. 5. Pormenor del Reloj nocturno del arzobispo Spínola, iluminado en su interior 


\section{BiBLIOGRAFÍA}

Alonso Morgado, José, Prelados sevillanos o Episcopologio de la Santa Iglesia Metropolitana y Patriarcal de Sevilla con noticias biográficas de los Sres. Obispos Auxiliares y otros relacionados con esta Santa Iglesia, Sevilla, Tipografía de Agapito López, 1906.

Álvarez Lopera, José, Valdés Leal. La vida de San Ambrosio, Madrid, Museo Nacional del Prado, 2003.

Aracil, Alfredo, Juego y artificio. Autómatas y otras ficciones en la cultura del Renacimiento a la llustración, Madrid, Cátedra, 1998.

Aranda Huete, Amelia, «El reloj, símbolo de poder en la Europa humanista», en Arte, poder y sociedad en la España de los siglos XV a XX, Madrid, CSIC, 2008, pp. 153-167.

Aranda Huete, Amelia (comp.), La medida del tiempo. Relojes de reyes en la corte española del siglo XVIII, Madrid, Patrimonio Nacional, 2011.

Aste di Antiaquariato Boetto, Antiquariato e pittura sec. XIX, Genova, 2016.

Bedini, Silvio A., «L'orologio notturno. Un'invenzione italiana del XVII secolo», en La misura del tempo. L'antico splendore dell'orologeria italiana dal XV al XVIII secolo, ed. Giuseppe Brusa, Trento, Castello del Buonconsiglio (Monumenti e collezioni provinciali), 2005, pp. 189-219.

Bold, John, John Webb. Architectural Theory and Practice in the Seventeenth Century, Oxford, Clarendon Press, 1989.

Brusa, Giuseppe, «ltalian Night Clock», Antiquarian Horology, 2, 9, marzo de 1975, pp. 159-168.

Brusa, Giuseppe, «ll più spettacolare sviluppo dell'orologeria italiana: i "notturni" dei fratelli Campani. Predecessori e seguaci al di qua e al di là delle Alpi», La Voce di Hora, 9, diciembre de 2000, pp. 3-34.

Brusa, Giuseppe, y Del Vecchio, Gian Carlo, «Orologi notturni», Kalòs, II, 8, diciembre de 1971, pp. 3-10.

Campani, Giuseppe, Discorso intorno a' soui muti Oriuoli, alle nouve Sfere Archimedee, et ad un'altra rarissima et utilissima inventione di Personaggio cospicuo, Roma, per Francesco Moneta, 1660.

Capel, Horacio, «La geografía como ciencia matemática mixta. La aportación del círculo jesuítico madrileño en el siglo XVII», Geo Crítica. Cuadernos críticos de geografía humana, V, 30, noviembre de 1980, pp. 1-35.

Caravaca de Coca, José María, «Lucas Valdés, maestro ilustrado en la Academia de la Real Compañía de Guardias Marinas de Cádiz», Revista General de Marina, 272, abril de 2017, pp. 455-469. 
Cardinal, Catherine, «L'horloge, un objet emblématique de la Renaissance», en Trésors d'horlogerie. Le temps et sa mesure du Moyen Âge à la Renaissance, Avignon, Éditions RMG, 1998, pp. 19-31.

Carducho, Vicente, Diálogos de la pintura. Su defensa, origen, esencia, definición, modos y diferencias, ed. Francisco Calvo Serraller, Madrid, Turner, 1979.

Ceán Bermúdez, Juan Agustín, Diccionario histórico de los más ilustres profesores de las Bellas Artes en España, t. V, Madrid, Imprenta de la Viuda de Ibarra, 1800.

Echeverría, José Miguel, Coleccionismo de relojes antiguos, 2. ${ }^{\text {a }}$ ed., León, Everest, 1979.

Egidi, Anatolio, I fratelli Campani da Castel San Felice. Vita e opere di tre inventori post-galileiani, Spoleto, Associazione Amici di Spoleto, 2011.

Fernández López, José, Lucas Valdés (1661-1725), Sevilla, Diputación de Sevilla, 2003.

Fuentes Lázaro, Sara, «La práctica de la cuadratura en España: el caso de Lucas Valdés (1661-1725)», Anales de Historia del Arte, 19, 2009, pp. 195-210.

Gámiz, Juan de, Oración panegírica a la ostentativa traslación de los huesos del Eminentísimo Sr. D. Agustín Espínola, Cardenal de la S. Iglesia Romana, y del IImo. y Revmo. Sr. D. Ambrosio Ignacio de Espínola y Guzmán, arzobispos de Sevilla, a la nueva iglesia del Colegio de la Compañía de Jesús, dedicado a la Purísima Concepción de María Santísima, que se celebró el día 22 de mayo de 1710, Sevilla, Francisco de Leefdael, 1710.

Garnier, Richard, y Hollis, Leo, Innovation \& Collaboration. The Origins and Early Development of the Pendulum Clock in London, Catálogo de exposición, Londres, Bonhams (3-14 de septiembre de 2018), 2018.

González Ramos, Roberto, Pedro Núñez de Villavicencio. Caballero pintor, Sevilla, Diputación de Sevilla, 1999.

González-Palacios, Alvar, Arredi e ornamenti alla corte di Roma, 1560-1795, Milán, Electa, 2004.

Gregato, Giorgio, «ll ritrovamento di un eccezionale "notturno" di Giuseppe Campani», La Voce di Hora, 8, junio de 2000, pp. 57-64.

Gregato, Giorgio, y Pippa, Luigi, «Un raro "notturno" di Giuseppe Campani», La Voce di Hora, 20, junio de 2006, pp. 63-67.

Herrera García, Francisco J., «Propaganda devocional y fuentes para la historia del arte. A propósito de una estampa de Lucas Valdés y dos escritos retóricos», Laboratorio de Arte, 13, 2000, pp. 103-121.

Loaysa, Juan de, Pésame a la S. Metropolitana, y Patriarcal Iglesia de Sevilla, en la reciente muerte de su Venerable Prelado el Ilustrísimo y Reverendísimo Señor el señor don Ambrosio Ignacio Spínola y Guzmán, con un breve resumen de su ejemplar vida, Sevilla, por Juan Antonio Tarazona, 1684. 
Montañés, Luis, Relojes, Madrid, Cipsa, 1986.

Montañés, Luis, El escape y el péndulo: literatura relojera, Madrid, Antiqvaria, 1991.

Morales, Alfredo J., «Un dibujo del Monumento de la Catedral de Sevilla por Lucas Valdés», Laboratorio de Arte, 6, 1993, pp. 157-167.

Morán Turina, José Miguel, y Checa Cremades, Fernando, El coleccionismo en España. De la cámara de maravillas a la galería de pinturas, Madrid, Cátedra, 1985.

Panofsky, Erwin, Estudios sobre Iconología, Madrid, Alianza, 2002.

Pérez Sánchez, Alfonso E., Pintura barroca en España (1600-1750), Madrid, Cátedra, 1992.

Pino León, Manuel, Anamorfosis y artificios perspectivos en la Península Ibérica entre los siglos XVI y XVIII, Tesis doctoral, Barcelona, Universidad de Barcelona (Facultad de Bellas Artes), 2015.

Quiles García, Fernando, Noticias de pintura (1700-1720). Fuentes para la historia del arte andaluz, Sevilla, Guadalquivir, 1990.

Réau, Louis, Iconografía del arte cristiano. Iconografía de los santos. De la A a la F, Barcelona, Ediciones del Serbal, 2000.

Revilla, Federico, Diccionario de iconografía y simbología, Madrid, Cátedra, 2009.

Ribadeneyra, Pedro de, Flos Sanctorum, de las Vidas de los Santos [1604-1609], vol. III, Madrid, por Joaquín Ibarra, 1761.

Rojas-Marcos González, Jesús, «Night Clock with Saint Ambrose Absolving the Emperor Theodosius», para la exposición A Tale of Two Kingdoms. The Art of Spain and Naples, en <http://www.colnaghi.com/exhibition.php?ide=15> [consultado el 8 de agosto de 2019].

Salazar Mir, Adolfo de, Los expedientes de limpieza de sangre de la Catedral de Sevilla (genealogías), Madrid, Hidalguía, 1995.

Simón Díaz, José, Historia del Colegio Imperial de Madrid, Madrid, Instituto de Estudios Madrileños, 1952.

Thompson, David, Clocks, London, BMP, 2004.

Valdivieso, Enrique, Pintura barroca sevillana, Sevilla, Guadalquivir, 2003.

Vega, Jesusa, Ciencia, arte e ilusión en la España ilustrada, Madrid, CSIC / Polifemo, 2010.

Vega, Pedro de la, Flos Sanctorum, Sevilla, en casa de Fernando Díaz, 1580.

Villegas, Alonso de, Flos Sanctorum, Madrid, en casa de Luis Sánchez, 1603.

Vorágine, Santiago de la, La leyenda dorada, Madrid, Alianza, 2008. 